\title{
The Totally Implantable Venous Access Device with Occurrence of Pneumothorax Still Remains an Issue
}

\author{
Isidoro Di Carlo ${ }^{1} \cdot$ Adriana Toro $^{2}$
}

Published online: 28 November 2016

(C) Société Internationale de Chirurgie 2016

We read with interest the article of Miccini et al. [1]. The authors focused on the usefulness of the ultrasonography (US) to detect the correct position of the catheter of a totally implantable venous access device (TIVAD) in relation to a chest X-ray or fluoroscopy. They performed a retrospective study that confirmed data in the literature. US is a perfect tool to establish the correct position of the tip of the catheter of a TIVAD, avoiding the side effects of radiological procedures.

However, the choice of technique and the vein to use are controversial. The cephalic vein, using surgical technique, was the first vein accessed by Niederuber when he placed the first TIVAD, and this access continued to be free of pneumothorax and other complications related to percutaneous access [2]. The authors reported a rate of PNX of $1 \%$. This rate (also if very low) is unacceptable because the authors used US, and because as surgeons, they may use surgical access avoiding any immediate complications. Furthermore, in cases in which the cephalic vein is not useful, other surgical vein access can be used, with a zero rate of immediate complications [3].

\section{References}

1. Miccini M, Cassini D, Gregori M, Gazzanelli S, Cassibba S, Biacchi D (2016) Ultrasound-guided placement of central venous port systems via the right internal jugular vein: Are chest X-ray and/or fluoroscopy needed to confirm the correct placement of the device? World J Surg 40:2353-2358

2. Biffi R, Toro A, Pozzi S, Di Carlo I (2014) Totally implantable vascular access devices 30 years after the first procedure. What has changed and what is still unsolved? Support Care Cancer 22:1705-1714

3. Di Carlo I, Barbagallo F, Toro A, Sofia M, Lombardo R, Cordio S (2005) External jugular vein cutdown approach, as a useful alternative, supports the choice of the cephalic vein for totally implantable access device placement. Ann Surg Oncol 12:570-573
Isidoro Di Carlo

idicarlo@unict.it

1 Department of Surgical Sciences and Advanced Technologies, University of Catania, Cannizzaro Hospital, Catania, Italy

2 General Surgery, Patti Hospital, Patti, ME, Italy 